\title{
Early and Midtreatment Mortality in Palliative Radiotherapy: Emphasizing Patient Selection in High-Quality End-of-Life Care
}

Matthew S. Ning, MD, MPH'1; Prajnan Das, MD, MS, MPH'; David I. Rosenthal, MD; Bouthaina S. Dabaja, MD'; Zhongxing Liao, MD'; Joe Y. Chang, MD, PhD'; Daniel R. Gomez, MD, MBA2; Ann H. Klopp, MD, PhD';

G. Brandon Gunn, MD'; Pamela K. Allen, MPH, PhD'; Paige L. Nitsch, MS'; Rachel B. Natter, MBA';

Tina M. Briere, $\mathrm{PhD}^{3}$; Joseph M. Herman, MD, MS, MSHCM${ }^{5}$; Rebecca Wells, PhD, MHSA;

Albert C. Koong, MD, $\mathrm{PhD}^{1}$; and Mary Frances McAleer, MD, $\mathrm{PhD}^{1}$

\section{ABSTRACT}

\begin{abstract}
Background: Palliative radiotherapy (RT) is effective, but some patients die during treatment or too soon afterward to experience benefit. This study investigates end-of-life RT patterns to inform shared decision-making and facilitate treatment consistent with palliative goals. Materials and Methods: All patients who died $\leq 6$ months after initiating palliative RT at an academic cancer center between 2015 and 2018 were identified. Associations with time-todeath, early mortality ( $\leq 30$ days), and midtreatment mortality were analyzed. Results: In total, 1,620 patients died $\leq 6$ months from palliative RT initiation, including 574 (34\%) deaths at $\leq 30$ days and $222(14 \%)$ midtreatment. Median survival was 43 days from RT start (95\% Cl, 41-45) and varied by site $(P<.001)$, ranging from 36 (head and neck) to 53 days (dermal/soft tissue). On multivariable analysis, earlier time-to-death was associated with osseous (hazard ratio [HR], 1.33; $P<.001)$ and head and neck $(H R, 1.45 ; P<.001)$ sites, multiple RT courses $\leq 6$ months (HR, 1.65; $P<.001)$, and multisite treatments (HR, $1.40 ; P=.008)$, whereas stereotactic technique $(H R, 0.77 ; P<.001)$ and more recent treatment year $(H R, 0.82 ; P<.001)$ were associated with longer survival. No difference in time to death was noted among patients prescribed conventional RT in 1 to 10 versus $>10$ fractions (median, 40 vs 47 days; $P=.272$ ), although the latter entailed longer courses. The 30 -day mortality group included 335 (58\%) inpatients, who were $27 \%$ more likely to die midtreatment $(P=.031)$. On multivariable analysis, midtreatment mortality among these inpatients was associated with thoracic (odds ratio [OR], 2.95; $P=.002$ ) and central nervous system (CNS; OR, 2.44; $P=.002$ ) indications, $>5$ fraction courses (OR, 3.27; $P<.001)$, and performance status of 3 to 4 $(\mathrm{OR}, 1.63 ; P=.050)$. Conversely, palliative/supportive care consultation was associated with decreased midtreatment mortality (OR, 0.60; $P=.045)$. Conclusions: Earlier referrals and hypofractionated courses ( $\leq 5-10$ treatments) should be routinely considered for palliative RT indications, given the short life expectancies of patients at this stage in their disease course. Providers should exercise caution for emergent thoracic and CNS indications among inpatients with poor prognoses due to high midtreatment mortality.
\end{abstract}

J Natl Compr Canc Netw 2021;19(7):805-813 doi: $10.6004 /$ jnccn.2020.7664

\section{Background}

Radiotherapy (RT) is an effective palliative tool for symptoms due to cancer, such as pain, ${ }^{1,2}$ neurologic compromise, ${ }^{3}$ mass effect, ${ }^{4}$ or bleeding, ${ }^{5}$ and remains an important mainstay of end-of-life (EoL) oncologic care. Although palliative RT is effective, some patients may not live long enough to experience its intended benefit. Prior reports of RT at EoL indicate a high proportion of patients die shortly after or during palliative RT. ${ }^{6-10}$ A large systematic review of 18 studies found that palliative RT utilization rates during the last month of life were up to $10 \%$ in all patients dying of cancer, ${ }^{11}$ and another study reported that an estimated 1 in 5 patients who received RT in their final 30 days of life spent $>10$ of those days receiving treatment. ${ }^{12}$ Separate institutions have indicated that only half of patients undergoing RT at EoL even complete these treatments courses before death. ${ }^{13,14}$ There are also are concerns regarding a shift toward more advanced RT technologies for these patients. ${ }^{15,16}$

Utilization of palliative care is complex and driven by multiple stakeholder perspectives and expectations, including those of consulting and referring providers, patients, and patients' families. The significant proportion of patients dying shortly after or during RT stems from difficulties in predicting life expectancies accurately for terminally ill patients. ${ }^{17,18}$ Provider tendencies to overestimate survival lead to challenges with tailoring palliative regimens and can result in disproportionately

${ }^{1}$ Department of Radiation Oncology, and ${ }^{3}$ Radiation Physics, The University of Texas MD Anderson Cancer Center, Houston, Texas; ${ }^{2}$ Department of Radiation Oncology, Memorial Sloan Kettering Cancer Center, New York, New York; ${ }^{4}$ Department of Management, Policy, and Community Health, University of Texas Health Science Center School of Public Health, Houston, Texas; and ${ }^{5}$ Department of Radiation Medicine, Zucker School of Medicine at Hofstra/ Northwell, Lake Success, New York. 
extensive treatments. ${ }^{19-23}$ Furthermore, such patients are often discharged to their referring providers for follow-up after completion of RT. Taken together, these practice trends call for more data to help guide physician decision-making and improve the quality of RT at EoL.

Therefore, this study examines patterns of early and midtreatment mortality for patients undergoing palliative RT at a large academic cancer center. This investigation is one of the largest institutional series to date, encompassing a wide range of tumor histologies, disease sites, RT prescriptions, and treatment indications, thereby contributing to prior reports in the literature. In addition to describing patterns of RT at EoL, this work evaluates specific clinical factors associated with early and midtreatment mortality, with the goal of helping guide formal communication in EoL care and shared decision-making strategies for terminally ill patients with cancer.

\section{Materials and Methods}

\section{Data Sources and Patient Population}

All patients who died within 6 months of starting RT at a large academic cancer center between January 1, 2015, and December 31, 2018, were identified through several databases: institutional daily inpatient reports, separate departmental lists, tumor registries, and state registries. These databases were consolidated, with systematic removal of duplicate entries and verification of patients within the electronic medical record. This study protocol was approved by the Institutional Review Board at the University of Texas MD Anderson Cancer Center. Palliative intent was an inclusion criterion, with definitive cases excluded from analysis.

Various clinical factors were collected, including age, treatment service, number of radiation fractions, RT technique, diagnosis, treatment site, indication, inpatient status, number of RT courses within the 6 months preceding death, number of simultaneous treatment sites, and treatment dates. Inpatient status was defined with respect to the date of CT simulation and/or first RT fraction. Performance status (PS) was recorded using 3 different scales: Karnofsky performance score (KPS), ECOG, and the Lansky score for pediatric patients. These were translated into a single PS index for analysis (range, $0-4$, analogous to ECOG), using empirically derived and validated interconversion systems. ${ }^{24-26}$

For treatment sites, vertebral bodies were categorized as osseous. Central nervous system (CNS) site encompassed intracranial disease, leptomeningeal or intramedullary cord involvement, and symptomatic perineural invasion (eg, cranial nerve involvement from skull base tumor) but did not include extrinsic cord compressions alone. Multiple sites $(>1)$ were defined with respect to separate fields/isocenters treated at the same time within the last course of RT, although these could still be classified under the same anatomic category (eg, femur and humeral bone metastases). At the same time, treatment sites were not mutually exclusive with respect to patient-level coding: for simultaneous sites, each treated region would be noted (eg, both thoracic and bone). Overlapping regions were similarly handled (eg, skull base tumor with symptomatic perineural involvement coded as CNS, bone, and head and neck simultaneously, yet representing a single treatment site or isocenter).

\section{Statistical Analyses}

The primary outcomes were time to death (computed from RT start), early mortality (defined as death within 30 days from RT start), and midtreatment mortality (with RT cessation before course completion). Midtreatment mortality included early cessation for discharge to hospice care if the patient died within 1 week of initiating RT; such patients were unlikely to continue RT at our institution after hospice transition. Notably, these endpoints were not mutually exclusive; all patients who died midtreatment also experienced early mortality (within 30 days from RT). For patients who received multiple RT courses within the 6 months preceding death, outcomes were calculated in reference to the last (most recent) treatment course.

The Kaplan-Meier method was used for survival time analysis, with log-rank tests to evaluate differences among groups. Univariate and multivariable Cox proportional hazards analyses were also conducted to identify clinical associations with time to death, generating hazard ratios (HRs) with $95 \%$ confidence intervals. For midtreatment mortality, univariate and multivariable logistic regression analyses were used to identify associations with clinical variables, generating odds ratios (ORs) with 95\% confidence intervals. Variables were also compared among groups by use of the Mann-Whitney $\mathrm{U}$ test for continuous variables and chi-square test for categorical variables. Statistical analyses were performed using SPSS Statistics, version 24 (IBM Corp). For all tests, a $P$ value $\leq .050$ was considered statistically significant.

\section{Results}

\section{Patient Characteristics}

Among 20,534 total RT courses delivered at our large academic center during this time frame (including definitive or palliative intent), a total of 1,912 patients were identified as having died within 6 months of initiating RT. Removal of 292 patients treated with definitive intent resulted in 1,620 study patients treated with palliative RT for analysis, with a median age of 63 years (interquartile range [IQR], 53-70 years) at time of death. Only 18 patients $(1 \%)$ were aged $<18$ years. Primary histology included lung (33\%), gastrointestinal (13\%), breast $(10 \%)$, 


\begin{tabular}{|c|c|c|c|c|c|}
\hline Variable & $\begin{array}{l}\text { Sites } \\
\text { n (\%) }\end{array}$ & $\begin{array}{c}\text { Time-to-Death } \\
\text { HR }(95 \% \mathrm{Cl})\end{array}$ & $\begin{array}{l}\text { Univariate } \\
P \text { Value }\end{array}$ & $\begin{array}{l}\text { Time-to-Death } \\
\text { HR }(95 \% \mathrm{Cl})\end{array}$ & $\begin{array}{c}\text { Multivariable } \\
\text { P Value }\end{array}$ \\
\hline \multicolumn{6}{|l|}{ Treatment site } \\
\hline CNS (vs non-CNS) & $523(32)$ & $1.03(0.93-1.14)$ & .588 & & \\
\hline Bone (vs nonbone) & $496(31)$ & $1.36(1.22-1.51)$ & $<.001$ & $1.33(1.19-1.48)$ & $<.001$ \\
\hline Thoracic (vs nonthoracic) & $275(17)$ & $0.87(0.77-0.99)$ & .038 & & \\
\hline Abdominopelvic & $198(12)$ & $0.87(0.75-1.01)$ & .065 & & \\
\hline Head and neck & $115(7)$ & $1.51(1.25-1.82)$ & $<.001$ & $1.45(1.19-1.77)$ & $<.001$ \\
\hline Dermal/Soft tissue & $104(6)$ & $0.78(0.64-0.96)$ & .016 & & \\
\hline Liver (vs nonliver) & $24(1.5)$ & $0.88(0.59-1.32)$ & .528 & & \\
\hline \multicolumn{6}{|l|}{ Primary histology } \\
\hline Lung (vs nonlung) & $534(33)$ & $1.06(0.96-1.18)$ & .270 & & \\
\hline Gastrointestinal & $206(13)$ & $1.08(0.94-1.24)$ & .289 & & \\
\hline Breast (vs nonbreast) & $156(10)$ & $0.99(0.84-1.17)$ & .895 & & \\
\hline Hematologic & $144(9)$ & $1.14(0.96-1.35)$ & .138 & & \\
\hline Genitourinary & $114(7)$ & $0.88(0.73-1.06)$ & .176 & & \\
\hline Head and neck & $92(6)$ & $1.06(0.85-1.30)$ & .619 & & \\
\hline Gynecologic & $75(5)$ & $0.79(0.63-1.00)$ & .052 & & \\
\hline \multicolumn{6}{|l|}{ RT modality } \\
\hline Stereotactic & $231(14)$ & $0.74(0.65-0.86)$ & $<.001$ & $0.77(0.67-0.89)$ & $<.001$ \\
\hline Standard RT & $1,389(86)$ & & & & \\
\hline \multicolumn{6}{|l|}{ Standard RT fractions } \\
\hline $11-26(3 \mathrm{D} / \mathrm{IMRT})$ & $193(14)$ & $0.92(0.79-1.07)$ & .277 & & \\
\hline $1-10(2 \mathrm{D} / 3 \mathrm{D})$ & $1,196(86)$ & & & & \\
\hline \multicolumn{6}{|l|}{ Treatment year } \\
\hline $2017-2018$ & $749(46)$ & $0.84(0.76-0.93)$ & .001 & $0.82(0.74-0.91)$ & $<.001$ \\
\hline $2015-2016$ & $871(54)$ & & & & \\
\hline \multicolumn{6}{|l|}{$\mathrm{RT}$ in last $6 \mathrm{mo}$} \\
\hline $2-5$ courses & $277(17)$ & $1.64(1.44-1.87)$ & $<.001$ & $1.65(1.44-1.88)$ & $<.001$ \\
\hline 1 course & $1,343(83)$ & & & & \\
\hline \multicolumn{6}{|l|}{ Number of sites treated } \\
\hline $2-3$ & $66(4)$ & $1.77(1.38-2.26)$ & $<.001$ & $1.40(1.09-1.80)$ & .008 \\
\hline 1 & $1,554(96)$ & & & & \\
\hline \multicolumn{6}{|l|}{ Patient age } \\
\hline $71-97$ y (vs $<50$ y) & $388(24)$ & $0.98(0.84-1.13)$ & .749 & & \\
\hline $50-70$ y $(v s<50$ y) & $928(57)$ & $0.93(0.82-1.06)$ & .273 & & \\
\hline $2-49$ y & 304 (19) & & & & \\
\hline
\end{tabular}

Abbreviations: CNS, central nervous system; HR, hazard ratio; IMRT, intensity-modulated radiotherapy; RT, radiotherapy.

${ }^{a}$ Cox proportional hazards for univariate and multivariable analyses of associations.

hematologic $(9 \%)$, genitourinary $(7 \%)$, head and neck (6\%), and gynecologic (5\%) cancers (Table 1). Anatomic treatment sites included CNS (32\%), bone (31\%), thoracic (17\%), abdominopelvic (12\%), head and neck (7\%), dermal/soft tissue (6\%), and liver (1.5\%). Treatment indications among patients with hematologic cancers $(\mathrm{n}=144)$ included (with overlapping regions) osseous sites in $42 \%$ (eg, multiple myeloma), dermal/soft tissue nodules in $21 \%$, CNS disease in $20 \%$, head and neck sites in $17 \%$, and abdominopelvic sites in $11 \%$.

\section{Treatment Details}

Multiple sites (2-3) were treated during the last RT course of 66 patients (4\%), whereas 277 patients (17\%) received multiple RT courses (2-5) within the 6 months preceding death. Of the last RT courses, 231 (14\%) involved 
stereotactic technique, $79 \%$ of which were for brain metastases and $13 \%$ were for osseous sites ( $11 \%$ vertebrae). Among patients receiving conventional (nonstereotactic) RT $(n=1,389)$, the median number of fractions was 10 (IQR, 5-10) per last treatment course. With respect to hypofractionation, osseous (40\%), head and neck (39\%), dermal/soft tissue (31\%), and abdominopelvic (28\%) sites were more likely to be treated with $\leq 5$ fractions, whereas thoracic $(17 \%)$ and CNS $(10 \%)$ sites were more often prescribed longer fractionation schemes $(P<.001)$. However, an increase in $\leq 5$-fraction courses was seen over time, from $24 \%$ in $2015-2016$ up to $30 \%$ in $2017-2018(P=.010)$.

\section{Survival Time From RT Start}

Among all patients dying within 6 months of palliative RT initiation, median survival was 43 days $(95 \% \mathrm{CI}$, 40.6-45.4) from RT start. Survival duration varied significantly by treatment site (log-rank, $P<.001$ ): 53 days for dermal/soft tissue (95\% CI, 44-62), 47 days for thoracic (95\% CI, 41-53), 47 days for CNS (95\% CI, 42-52), 46 days for abdominopelvic (95\% CI, 37-55), 38 days for bone (95\% CI, 33-43), and 36 days for head and neck (95\% CI, 32-40) (Figure 1). For patients treated with conventional RT techniques $(n=1,389)$, no significant difference was noted in survival time among those prescribed $>10$ versus 1 to 10 RT fractions (log-rank, $P=.272$; median, 47 [95\% CI, 48-56] vs 40 days [95\% CI, 38-42], respectively) (Figure 2). On multivariable analysis, multisite treatments (HR, $1.40 ; P=.008)$, multiple RT courses within 6 months (HR, 1.65; $P<.001$ ), and treatment of osseous (HR, 1.33; $P<.001)$ and head and neck sites (HR, $1.45 ; P<.001$ ) were associated with shorter time to death, whereas stereotactic techniques (HR, 0.77; $P<.001)$ and more recent treatment period (2017-2018; HR, 0.82; $P<.001)$ were associated with longer survival duration (Table 1).

\section{Early Mortality Within 30 Days From RT Start}

Of the 1,620 study patients, $574(35 \%)$ died within 30 days, at a median of 18 days from RT start $(95 \%$ CI, 16.7-19.3); median PS was 2 (IQR, 2-3). The proportion of patients dying within 30 days varied significantly per treatment site $(P<.001)$ : bone $(43 \%)$, head and neck (39\%), CNS (32\%), abdominopelvic (30\%), thoracic (24.5\%), and dermal/soft tissue (22\%) (Figure 1B), yet no differences were noted with respect to primary tumor histology $(P=.07)$. Compared with the remaining 1,046 patients, neither prescribed fractions $(P=.130)$ nor patient age $(P=.123)$ were significantly different; however, fewer of the patients treated with conventional RT techniques who died within 30 days were treated with stereotactic technique $(10 \%$ vs $17 \% ; P<.001)$. Patients within the early mortality group treated for thoracic disease $(n=74)$ presented nonexclusively with dyspnea
A

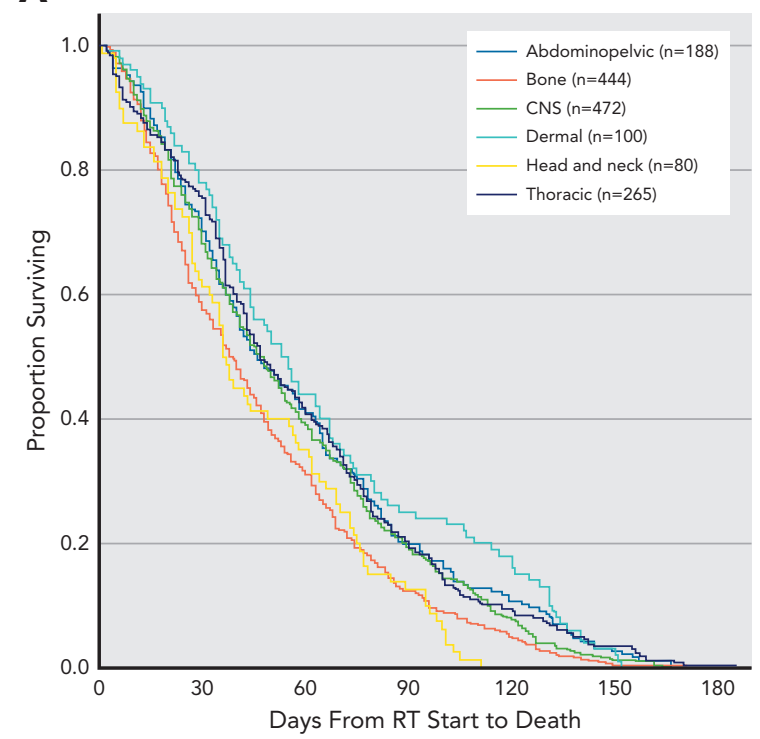

B

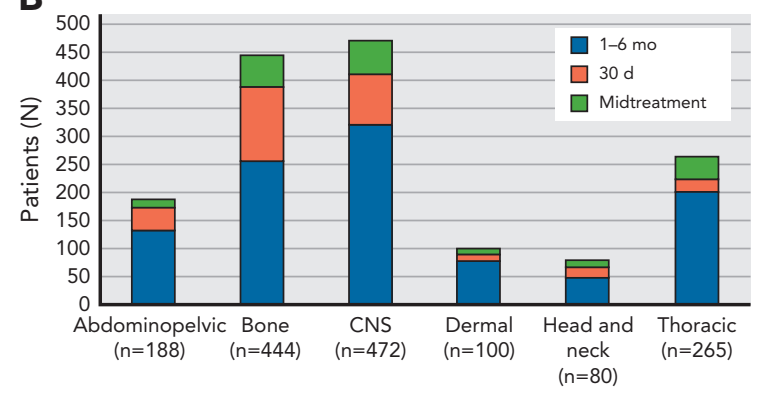

Figure 1. (A) Median time-to-death by treatment site among patients who died $\leq 6$ months from palliative RT. (B) Proportion of patients dying within 30 days of RT initiation by anatomic site. Although separated for presentation, patients who died midtreatment (green) also fall into the early mortality group (orange).

Abbreviations: CNS, central nervous system; RT, radiotherapy.

(66\%; due to airway compromise or obstruction), cough (22\%; $12 \%$ with hemoptysis), chest pain $(19 \%)$, and/or superior vena cava syndrome (12\%).

\section{Midtreatment Mortality Among All Patients}

Among the 1,620 study patients, 222 (14\%) died midway through RT before course completion, at a median 15 days (IQR, 14-16) after RT initiation. On multivariable analysis controlling for potential confounders (Table 2), treatment of multiple sites (OR, 2.16; $P=.009)$, longer RT courses ( $>10$ fractions; OR, 2.02; $P<.001$ ), and CNS site (OR, 1.93; $P<.001)$ were associated with midtreatment mortality, whereas breast histology (OR, 0.49; $P=.018$ ) and abdominopelvic site (OR, $0.54 ; P=.026$ ) were associated with decreased likelihood of death during treatment. Notably, neither age nor multiple RT courses within 6 months were significant factors on analysis. 


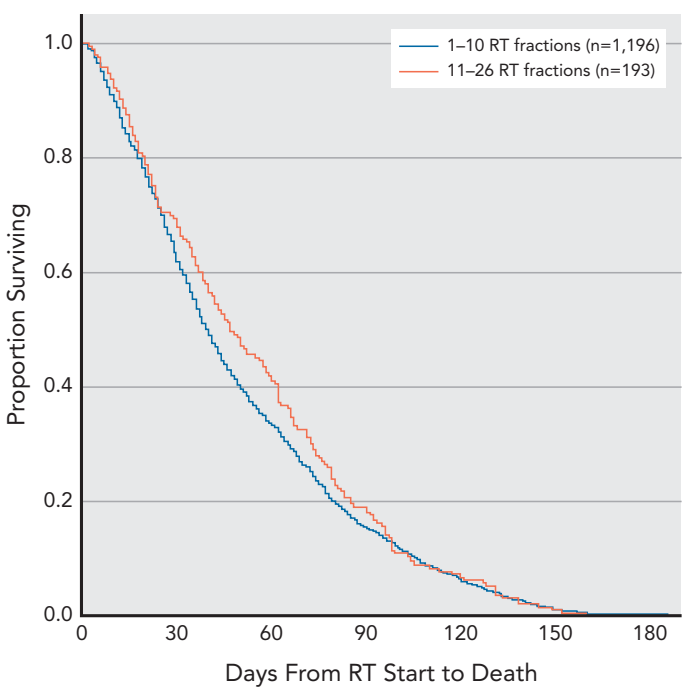

Figure 2. Survival time from RT start for patients who died $\leq 6$ months from palliative RT and were treated with standard techniques $(\mathrm{N}=1,389)$. Patients treated with stereotactic techniques were excluded from this analysis $(n=231)$.

Abbreviation: RT, radiotherapy.

\section{Midtreatment Mortality Among Inpatients}

Of the 574 patients dying within 30 days, 335 (58\%) underwent CT-simulation and/or first fraction of RT during hospital admission. Compared with outpatients who died within 30 days, admitted patients also had poorer PS (3-4; $55 \%$ vs $24 \% ; P<.001)$ and were more likely to die midtreatment ( $42 \%$ vs $33.5 \%$; $P=.031$ ), although no difference in prescribed fractions was noted with respect to admission $(P=.152)$. Among these 335 inpatients, multivariable analysis demonstrated that thoracic sites (OR, 2.95; $P=.002$ ), CNS sites (OR, 2.44; $P=.002)$, longer RT courses ( $>5$ fractions; OR, 3.27; $P<.001$ ), and poor PS ( $3-4$; OR, $1.63 ; P=.050$ ) were variables associated with midtreatment death (Table 3). After chart review, 29 of the 50 inpatient thoracic cases (58\%) and 52 of the 98 inpatient CNS cases (53\%) died before RT completion. However, palliative/supportive care consultation, which took place for $61 \%$ of inpatients, was associated with decreased midtreatment mortality (OR, $0.60 ; P=.045)$. In addition, increased service referrals were observed over time, from $52 \%$ in $2015-2016$ up to $69 \%$ in $2017-2018(P=.002)$.

\section{Discussion}

This study is one of the largest institutional analyses investigating patterns of early and midtreatment mortality after palliative RT, encompassing a wide range of tumor histologies, disease sites, RT prescriptions, and treatment indications. Among the 1,620 patients who died $\leq 6$ months from start of palliative RT at our institution, the most salient findings are as follows: (1) median survival ranges 1 to 2 months among these early patients, one-third of whom die $<30$ days and one-seventh of whom die midtreatment; (2) extended RT courses are not associated with longer survival among these patients, but they impart longer treatment courses and carry a greater likelihood of midtreatment mortality; (3) inpatients with emergent thoracic or CNS indications are at high risk for midtreatment death; and (4) palliative/supportive care consultation is associated with decreased likelihood of mortality during treatment.

The high proportion of patients dying during or shortly after palliative RT initiation at this single institution is consistent with prior reports of RT at EoL, ${ }^{6-11,13,14}$ a pattern that stems from difficulties in predicting life expectancies accurately for terminally ill patients. ${ }^{17,18}$ Provider tendencies to overestimate survival lead to delayed patient referrals and challenges with tailoring palliative regimens, which can result in disproportionately extensive treatments. ${ }^{19-23}$ Therefore, these data call for additional efforts toward improving life expectancy assessments, perhaps through predictive modeling methods combining prognostic factors. ${ }^{27-37}$ Notable examples include the Chow, ${ }^{33}$ $\mathrm{NEAT}^{38}$ and TEACHH ${ }^{39}$ models, each with demonstrated utility for this setting. Consistent with these validated prognostic tools, our study found significant associations with respect to metastatic site, hospital admission, PS, and primary histology to a lesser extent. In addition, multisite treatments and receipt of multiple RT courses, as surrogates of metastatic disease burden, were also found to be associated with study endpoints.

Moreover, several practical conclusions may be derived from these data to help guide physician decisionmaking. For example, although palliative RT is effective, the limited survival among those who receive it indicates that RT is unlikely to impart a survival benefit among patients with poor prognoses, thus highlighting the importance of early patient referrals at symptom onset and appropriately tailoring RT prescriptions. To this end, our data demonstrate that extended RT courses were not associated with longer survival among patients receiving palliative care who died within 6 months from standard RT, although they were associated with longer treatment durations and greater likelihood of midtreatment mortality among such patients. Although select patients with stage IV disease may benefit from advanced modalities ${ }^{40-43}$ (as demonstrated by the longer survival observed for our stereotactic cohort), in general, shorter hypofractionated courses ( $\leq 5-10$ treatments) and standard complexity techniques should be prioritized among palliative cases to minimize treatment duration.

These findings are consistent with the ASTRO Choosing Wisely guidelines for EoL RT, $, 244,45$ which advocate for shorter palliative courses among patients with limited life expectancies. Our study reassuringly demonstrates increased use of $\leq 5$-fraction prescriptions over time; however, these courses were most often assigned for 
Table 2. Characteristics of All Patients Who Died $\leq 6$ Months From Palliative $R T(n=1,620)$

\begin{tabular}{|c|c|c|c|c|c|}
\hline Variable & $\begin{array}{l}\text { Sites } \\
\text { n (\%) }\end{array}$ & $\begin{array}{l}\text { Midtreatment Death } \\
\text { OR }(95 \% \mathrm{CI})\end{array}$ & $\begin{array}{l}\text { Univariate } \\
P \text { Value }\end{array}$ & $\begin{array}{l}\text { Midtreatment Death } \\
\text { OR }(95 \% \mathrm{Cl})\end{array}$ & $\begin{array}{c}\text { Multivariable } \\
P \text { Value }\end{array}$ \\
\hline \multicolumn{6}{|l|}{ Treatment site } \\
\hline CNS (vs non-CNS) & $523(32)$ & $1.27(0.95-1.71)$ & .111 & $1.93(1.39-2.67)$ & $<.001$ \\
\hline Bone (vs nonbone) & $496(31)$ & $1.13(0.84-1.53)$ & .431 & & \\
\hline Thoracic (vs nonthoracic) & $275(17)$ & $1.38(0.97-1.96)$ & .074 & & \\
\hline Abdominopelvic & $198(12)$ & $0.56(0.33-0.94)$ & .027 & $0.54(0.32-0.93)$ & .026 \\
\hline Head and neck & $115(7)$ & $1.95(1.23-3.10)$ & .005 & & \\
\hline Dermal/Soft tissue & $104(6)$ & $0.81(0.44-1.51)$ & .508 & & \\
\hline Liver (vs nonliver) & $24(1.5)$ & $0.54(0.13-2.32)$ & .410 & & \\
\hline \multicolumn{6}{|l|}{ Primary histology } \\
\hline Lung (vs nonlung) & $533(33)$ & $1.20(0.89-1.61)$ & .230 & & \\
\hline Gastrointestinal & $205(13)$ & $0.86(0.56-1.31)$ & .484 & & \\
\hline Breast (vs nonbreast) & $155(10)$ & $0.60(0.34-1.05)$ & .074 & $0.49(0.27-0.88)$ & .018 \\
\hline Hematologic & $144(9)$ & $2.21(1.47-3.34)$ & $<.001$ & & \\
\hline Genitourinary & $114(7)$ & $1.03(0.60-1.78)$ & .915 & & \\
\hline Head and beck & $92(6)$ & $1.04(0.57-1.90)$ & .902 & & \\
\hline Gynecologic & $75(5)$ & $0.64(0.29-1.41)$ & .264 & & \\
\hline \multicolumn{6}{|l|}{ RT modality } \\
\hline Stereotactic & $231(14)$ & $0.023(0.01-0.17)$ & $<.001$ & & \\
\hline Standard RT & $1,389(86)$ & & & & \\
\hline \multicolumn{6}{|l|}{ Standard RT fractions } \\
\hline 11-26 (3D/IMRT) & $193(14)$ & $1.89(1.31-2.73)$ & .001 & $2.02(1.39-2.93)$ & $<.001$ \\
\hline $1-10(2 \mathrm{D} / 3 \mathrm{D})$ & $1,196(86)$ & & & & \\
\hline \multicolumn{6}{|l|}{ Treatment year } \\
\hline $2017-2018$ & $749(46)$ & $1.01(0.76-1.34)$ & .958 & & \\
\hline $2015-2016$ & $871(54)$ & & & & \\
\hline \multicolumn{6}{|l|}{$\mathrm{RT}$ in last $6 \mathrm{mo}$} \\
\hline $2-5$ courses & 277 (17) & $1.04(0.72-1.51)$ & .842 & & \\
\hline 1 course & $1,343(83)$ & & & & \\
\hline \multicolumn{6}{|l|}{ Number of sites treated } \\
\hline $2-3$ & $66(4)$ & $2.69(1.55-4.68)$ & $<.001$ & $2.16(1.21-3.87)$ & .009 \\
\hline 1 & $1,554(96)$ & & & & \\
\hline \multicolumn{6}{|l|}{ Patient age } \\
\hline $71-97$ y (vs $<50$ y) & $388(24)$ & $0.65(0.42-1.01)$ & .055 & & \\
\hline $50-70$ y (vs $<50$ y) & $928(57)$ & $0.88(0.62-1.27)$ & .503 & & \\
\hline $2-49$ y & 304 (19) & & & & \\
\hline
\end{tabular}

Abbreviations: CNS, central nervous system; IMRT, intensity-modulated radiotherapy; OR, odds ratio; RT, radiotherapy.

aLogistic regression for univariate and multivariable analyses of associations.

bone or head and neck, with most nonstereotactic CNS and thoracic sites still treated with longer courses. Although perhaps specific to our institution, this practice pattern could stem from a relative lack of data for certain anatomic sites. Multiple studies have demonstrated the noninferiority of shorter regimens for palliation, ${ }^{5,46-49}$ but these have largely focused on bone, head and neck, and only recently abdominopelvic indications. Data on progressively hypofractionated courses ( $\leq 5$ treatments) in other sites may encourage their increased use.

Additional study findings of clinical utility entailed the inpatient population with cancer. Hospital admission has been repeatedly associated with poor prognosis among patients receiving palliative $\mathrm{RT}^{6,7,9,10}$; however, inpatient 


\section{Table 3. Characteristics of Inpatients Who Died Within 30 Days From Palliative RT ( $=335$ )}

\begin{tabular}{|c|c|c|c|c|c|}
\hline Variable & $\begin{array}{l}\text { Sites } \\
\text { n (\%) }\end{array}$ & $\begin{array}{l}\text { Midtreatment Death } \\
\text { OR }(95 \% \mathrm{CI})\end{array}$ & $\begin{array}{l}\text { Univariate } \\
P \text { Value }{ }^{a}\end{array}$ & $\begin{array}{l}\text { Midtreatment Death } \\
\text { OR }(95 \% \mathrm{Cl})\end{array}$ & $\begin{array}{c}\text { Multivariable } \\
\text { P Value }\end{array}$ \\
\hline \multicolumn{6}{|l|}{ Treatment site } \\
\hline Thoracic (vs nonthoracic) & $50(15)$ & $2.10(1.14-3.87)$ & .017 & $2.95(1.49-5.81)$ & .002 \\
\hline Bone (vs nonbone) & $156(47)$ & $0.52(0.33-0.81)$ & .004 & & \\
\hline CNS (vs non-CNS) & $98(29)$ & $1.85(1.15-2.97)$ & .012 & $2.44(1.40-4.25)$ & .002 \\
\hline Head and neck & $34(10)$ & $1.74(1.07-2.83)$ & .025 & & \\
\hline Abdominopelvic & $36(11)$ & $0.65(0.31-1.35)$ & .247 & & \\
\hline Dermal/Soft tissue & $18(5)$ & $1.38(0.54-3.58)$ & .503 & & \\
\hline Liver (vs nonliver) & $6(2)$ & $0.68(0.12-3.74)$ & .653 & & \\
\hline \multicolumn{6}{|l|}{ Primary histology } \\
\hline Lung (vs nonlung) & $99(30)$ & $1.13(0.70-1.81)$ & .622 & & \\
\hline Hematologic & $50(15)$ & $1.61(0.79-3.27)$ & .192 & & \\
\hline Gastrointestinal & $42(12)$ & $0.62(0.35-1.11)$ & .108 & & \\
\hline Breast (vs nonbreast) & $32(10)$ & $0.59(0.27-1.29)$ & .184 & & \\
\hline Genitourinary & $22(7)$ & $1.39(0.59-3.30)$ & .456 & & \\
\hline Head and neck & $15(5)$ & $0.90(0.31-2.59)$ & .848 & & \\
\hline Gynecologic & $13(4)$ & $1.17(0.39-3.57)$ & .779 & & \\
\hline \multicolumn{6}{|l|}{ Treatment year } \\
\hline 2017-2018 & $161(48)$ & $0.94(0.61-1.45)$ & .783 & & \\
\hline 2015-2016 & $174(52)$ & & & & \\
\hline \multicolumn{6}{|l|}{ RT modality } \\
\hline Stereotactic & $13(4)$ & NA & .998 & & \\
\hline Standard RT & $322(96)$ & & & & \\
\hline \multicolumn{6}{|l|}{ Standard RT fractions } \\
\hline 6-22 (2D/3D/IMRT) & $203(63)$ & $3.43(2.09-5.61)$ & $<.001$ & $3.27(1.92-5.57)$ & $<.001$ \\
\hline $1-5(2 D / 3 D)$ & $119(37)$ & & & & \\
\hline \multicolumn{6}{|l|}{ RT in last $6 \mathrm{mo}$} \\
\hline $2-5$ courses & 277 (83) & $0.51(0.30-0.87)$ & .013 & & \\
\hline 1 course & $1,343(17)$ & & & & \\
\hline \multicolumn{6}{|l|}{ Number of sites treated } \\
\hline $2-3$ & $26(8)$ & $1.40(0.63-3.11)$ & .415 & & \\
\hline 1 & $309(92)$ & & & & \\
\hline \multicolumn{6}{|l|}{ Performance status } \\
\hline $3-4$ & $183(55)$ & $1.52(0.98-2.36)$ & .062 & $1.63(1.00-2.67)$ & .050 \\
\hline $0-2$ & $152(45)$ & & & & \\
\hline \multicolumn{6}{|l|}{ Patient age } \\
\hline $71-90$ y (vs $<50$ y) & $67(20)$ & $0.73(0.38-1.43)$ & .364 & & \\
\hline $50-70$ y $(v s<50$ y) & $183(55)$ & $1.33(0.79-2.24)$ & .284 & & \\
\hline $2-49 y$ & $85(25)$ & & & & \\
\hline \multicolumn{6}{|l|}{ Palliative consultation } \\
\hline Yes & $204(61)$ & $0.62(0.40-0.96)$ & .032 & $0.60(0.37-0.99)$ & .045 \\
\hline No & 131 (39) & & & & \\
\hline
\end{tabular}

Abbreviations: CNS, central nervous system; IMRT, intensity-modulated radiotherapy; NA, not applicable; OR, odds ratio; RT, radiotherapy. aLogistic regression for univariate and multivariable analyses of associations. 
consultation requests are common practice for radiation oncologists. Notably, our data indicate that emergent thoracic and CNS indications among inpatients are highly associated with midtreatment mortality and poor PS. Although RT in general can be an extremely useful tool for palliation of spine, brain, or thoracic metastases, ${ }^{44,50-53}$ these inpatient thoracic and CNS cases represented emergent scenarios known to impart poor survival among patients with end-stage cancer, such as airway compromise, severe hemoptysis, altered mental status, seizures, or symptomatic leptomeningeal disease. ${ }^{10,13}$ Our data indicate that such patients are more likely to die midtreatment before RT completion.

Therefore, although palliative RT in general is highly effective for a range of indications, with symptomatic improvement noted even among patients surviving $>30$ days, ${ }^{11}$ providers, patients, and families should remain realistic about the potential benefits for emergent inpatient cases, particularly those with poor PS. At the very least, these circumstances should serve as clinical prompts for hospice referral and goals-of-care discussions with patients and families. In support of this, our study found that palliative/supportive care consultation was associated with decreased midtreatment mortality among inpatients, likely through facilitation of advanced planning conversations and coordination of hospice care transition. Although potentially specific to our institution, we also observed a reassuring increase in such referrals over time, suggesting that more providers recognize the benefit of supportive measures at EoL.

\section{Conclusions}

This study analyzes patterns of early and midtreatment mortality of patients who died within 6 months of palliative RT at a large academic cancer center. The major limitation of this work is its single-institution, retrospective nature, reflecting practice patterns specific to our group of $>70$ physicians. Here, palliative RT is largely driven by direct referrals from providers of other disciplines (eg, medical oncology, surgical oncology) who are also subspecialized to treating 1 to 2 disease sites. The observed tertiary cancer center outcomes may not be fully generalizable toward the distinct patient populations treated in community-based practice.
This work also shares inherent biases associated with studies of decedents, ${ }^{54}$ and the 6-month time frame further selected for patients with particularly poor prognoses, limiting our ability to integrate the validated scoring indices of prior models. ${ }^{33,38,39}$ Extent of metastatic disease burden (a significant prognostic factor) was also not quantified via standardized method, with multisite treatments and receipt of multiple RT courses used as surrogate measures. Additional confounders include death from nonmalignant causes (eg, pancytopenia in the setting of hematologic malignancies). Furthermore, this study does not characterize or quantify the intent of therapy, whether goals of palliation (notably symptomatic improvement) were achieved, and the incidence or severity of toxicities (which can significantly impact quality of life in the palliative setting). The design also lacks examination of sociodemographic and cultural factors, which factor into the complexity of palliative care.

However, despite these limitations, our study benefits from being one of the largest series of its kind to date, encompassing a wide range of tumor histologies, disease sites, RT prescriptions, and treatment indications. Taken together, these data strongly advocate for the use of shorter hypofractionated treatment courses during palliative RT for terminally ill patients with cancer, and thereby help inform goals-of-care discussions and shared decision-making strategies to promote high-quality EoL cancer care.

Submitted April 24, 2020; final revision received August 31, 2020; accepted for publication September 28, 2020. Published online April 20, 2021

Previous presentation: Presented as an oral abstract at the 2019 ASTRO Annual Meeting; September 15-18, 2019; Chicago, Illinois. Abstract 1084

Author contributions: Study concept and design: Ning, McAleer. Data acquisition: Ning, Das, Rosenthal, Chang, Allen, Briere, Wells, McAleer. Data analysis and interpretation: Ning, Das, Rosenthal, Chang, Allen, Briere, Wells, McAleer. Manuscript preparation: All authors. Critical revision: All authors.

Disclosures: Dr. Herman reports receiving consulting fees from 1440 Foundation and Medtronic. The remaining authors have disclosed that they have not received any financial consideration from any person or organization to support the preparation, analysis, results, or discussion of this article.

Funding: Research reported in this article was supported in part by the NIH/ $\mathrm{NCl}$ Cancer Center Support (Core) grant CA016672 to The University of Texas MD Anderson Cancer Center.

Disclaimer: The content is solely the responsibility of the authors and does not necessarily represent the official views of the NIH.

Correspondence: Matthew S. Ning, MD, MPH, Department of Radiation Oncology, The University of Texas MD Anderson Cancer Center, Unit 0097, 1515 Holcombe Boulevard, Houston, TX 77030. Email: msning@mdanderson.org

\section{References}

1. Chow E, Harris K, Fan G, et al. Palliative radiotherapy trials for bone metastases: a systematic review. J Clin Oncol 2007;25: 1423-1436.

2. Lutz S, Berk L, Chang E, et al. Palliative radiotherapy for bone metastases: an ASTRO evidence-based guideline. Int J Radiat Oncol Biol Phys 2011; 79:965-976.

3. Wong J, Hird A, Zhang L, et al. Symptoms and quality of life in cancer patients with brain metastases following palliative radiotherapy. Int $J$ Radiat Oncol Biol Phys 2009;75:1125-1131.
4. Grewal AS, Jones J, Lin A. Palliative radiation therapy for head and neck cancers. Int J Radiat Oncol Biol Phys 2019;105:254-266.

5. Sapienza LG, Ning MS, Jhingran A, et al. Short-course palliative radiation therapy leads to excellent bleeding control: a single centre retrospective study. Clin Transl Radiat Oncol 2018;14:40-46.

6. Ellsworth SG, Alcorn SR, Hales RK, et al. Patterns of care among patients receiving radiation therapy for bone metastases at a large academic institution. Int J Radiat Oncol Biol Phys 2014;89: 1100-1105. 
7. Wu SY, Singer L, Boreta $L$, et al. Palliative radiotherapy near the end of life. BMC Palliat Care 2019;18:29.

8. Patel A, Dunmore-Griffith J, Lutz S, et al. Radiation therapy in the last month of life. Rep Pract Oncol Radiother 2013;19:191-194.

9. Kruser JM, Rakhra SS, Sacotte RM, et al. Intensive care unit outcomes among patients with cancer after palliative radiation therapy. Int J Radiat Oncol Biol Phys 2017;99:854-858.

10. Grade M, Koenig J, Qian Y, et al. Outcomes and characteristics of patients treated with emergent palliative radiation therapy. Pract Radiat Oncol 2019;9:e203-209.

11. Park KR, Lee CG, Tseng YD, et al. Palliative radiation therapy in the last 30 days of life: a systematic review. Radiother Oncol 2017;125:193-199.

12. Guadagnolo BA, Liao KP, Elting $L$, et al. Use of radiation therapy in the last 30 days of life among a large population-based cohort of elderly patients in the United States. J Clin Oncol 2013;31:80-87.

13. Gripp S, Mjartan S, Boelke E, et al. Palliative radiotherapy tailored to life expectancy in end-stage cancer patients: reality or myth? Cancer 2010; 116:3251-3256

14. Toole M, Lutz S, Johnstone PAS. Radiation oncology quality: aggressiveness of cancer care near the end of life. J Am Coll Radiol 2012;9:199-202.

15. Guadagnolo BA, Liao KP, Giordano SH, et al. Increasing use of advanced radiation therapy technologies in the last 30 days of life among patients dying as a result of cancer in the United States. J Oncol Pract 2014;10: e269-276.

16. Guadagnolo BA, Huo J, Liao KP, et al. Changing trends in radiation therapy technologies in the last year of life for patients diagnosed with metastatic cancer in the United States. Cancer 2013;119:1089-1097.

17. Christakis NA, Lamont EB. Extent and determinants of error in doctors' prognoses in terminally ill patients: prospective cohort study. BMJ 2000; 320:469-472.

18. Gripp S, Moeller S, Bölke E, et al. Survival prediction in terminally ill cancer patients by clinical estimates, laboratory tests, and self-rated anxiety and depression. J Clin Oncol 2007;25:3313-3320.

19. Chow E, Davis L, Panzarella T, et al. Accuracy of survival prediction by palliative radiation oncologists. Int J Radiat Oncol Biol Phys 2005;61: 870-873.

20. Barnes EA, Chow E, Tsao MN, et al. Physician expectations of treatment outcomes for patients with brain metastases referred for whole brain radiotherapy. Int J Radiat Oncol Biol Phys 2010;76:187-192.

21. Tseng YD, Krishnan MS, Sullivan AJ, et al. How radiation oncologists evaluate and incorporate life expectancy estimates into the treatment of palliative cancer patients: a survey-based study. Int J Radiat Oncol Biol Phys 2013;87:471-478.

22. Sborov K, Giaretta S, Koong A, et al. Impact of accuracy of survival predictions on quality of end-of-life care among patients with metastatic cancer who receive radiation therapy. J Oncol Pract 2019;15:e262-270.

23. Razvi Y, Chan S, Zhang L, et al. Are we better a decade later in the accuracy of survival prediction by palliative radiation oncologists? Ann Palliat Med 2019;8:150-158.

24. Oken MM, Creech RH, Tormey DC, et al. Toxicity and response criteria of the Eastern Cooperative Oncology Group. Am J Clin Oncol 1982;5: 649-655.

25. Ma C, Bandukwala S, Burman D, et al. Interconversion of three measures of performance status: an empirical analysis. Eur J Cancer 2010;46: 3175-3183.

26. Buccheri G, Ferrigno D, Tamburini M. Karnofsky and ECOG performance status scoring in lung cancer: a prospective, longitudinal study of 536 patients from a single institution. Eur J Cancer 1996;32A:1135-1141.

27. Chow $E$, Abdolell M, Panzarella $T$, et al. Validation of a predictive model for survival in metastatic cancer patients attending an outpatient palliative radiotherapy clinic. Int J Radiat Oncol Biol Phys 2009;73:280-287.

28. Chow E, Abdolell M, Panzarella $T$, et al. Recursive partitioning analysis of prognostic factors for survival in patients with advanced cancer. Int J Radiat Oncol Biol Phys 2009;73:1169-1176.

29. Gensheimer MF, Henry AS, Wood DJ, et al. Automated survival prediction in metastatic cancer patients using high-dimensional electronic medical record data. J Natl Cancer Inst 2019;111:568-574.

30. Gwilliam B, Keeley V, Todd C, et al. Development of Prognosis in Palliative care Study (PiPS) predictor models to improve prognostication in advanced cancer: prospective cohort study. BMJ Support Palliat Care 2015; 5:390-398.

31. Baba M, Maeda I, Morita T, et al. Survival prediction for advanced cancer patients in the real world: a comparison of the Palliative Prognostic Score Delirium-Palliative Prognostic Score, Palliative Prognostic Index and modified Prognosis in Palliative Care Study predictor model. Eur J Cancer 2015;51:1618-1629.

32. Kerstens $P, Y i$ M, James M. Radiotherapy for metastatic spinal cord compression; can the Rades score predict survival? Asia Pac J Clin Oncol 2019;15:331-336.

33. Chow $\mathrm{E}$, Abdolell M, Panzarella $\mathrm{T}$, et al. Predictive model for survival in patients with advanced cancer. J Clin Oncol 2008;26:5863-5869.

34. Kubota H, Soejima T, Sulaiman NS, et al. Predicting the survival of patients with bone metastases treated with radiation therapy: a validation study of the Katagiri scoring system. Radiat Oncol 2019;14:13

35. Verhoef MJ, de Nijs EJM, Fiocco M, et al. Surprise question and performance status indicate urgency of palliative care needs in patients with advanced cancer at the emergency department: an observational cohor study. J Palliat Med 2020;23:801-808.

36. Jang RW, Caraiscos VB, Swami N, et al. Simple prognostic model for patients with advanced cancer based on performance status. J Onco Pract 2014;10:e335-341.

37. Kang J, Ning MS, Feng $\mathrm{H}$, et al. Predicting 5 -year progression and surviva outcomes for early stage non-small cell lung cancer treated with stereotactic ablative radiation therapy: development and validation of robust prognostic nomograms. Int J Radiat Oncol Biol Phys 2020;106:90-99.

38. Zucker A, Tsai CJ, Loscalzo J, et al. The NEAT predictive model for survival in patients with advanced cancer. Cancer Res Treat 2018;50:1433-1443.

39. Krishnan MS, Epstein-Peterson Z, Chen YH, et al. Predicting life expectancy in patients with metastatic cancer receiving palliative radiotherapy: the TEACHH model. Cancer 2014;120:134-141.

40. Ning MS, Deegan BJ, Ho JC, et al. Low incidence of late failure and toxicity after spine stereotactic radiosurgery: secondary analysis of phase I/II trials with long-term follow-up. Radiother Oncol 2019;138:80-85.

41. Ning MS, Gomez DR, Heymach JV, et al. Stereotactic ablative body radiation for oligometastatic and oligoprogressive disease. Transl Lung Cancer Res 2019;8:97-106.

42. Ning MS, Ahobila V, Jhingran A, et al. Outcomes and patterns of relapse after definitive radiation therapy for oligometastatic cervical cancer. Gynecol Oncol 2018;148:132-138.

43. Johung KL, Yeh N, Desai NB, et al. Extended survival and prognostic factors for patients with ALK-rearranged non-small-cell lung cancer and brain metastasis. J Clin Oncol 2016;34:123-129.

44. Rodrigues G, Videtic GMM, Sur R, et al. Palliative thoracic radiotherapy in lung cancer: an American Society for Radiation Oncology evidence-based clinical practice guideline. Pract Radiat Oncol 2011;1:60-71.

45. Wallace AS, Fiveash JB, Williams CP, et al. Choosing wisely at the end of life: use of shorter courses of palliative radiation therapy for bone metastasis. Int J Radiat Oncol Biol Phys 2018;102:320-324.

46. Liu $Y$, von Eyben R, Kidd EA. Consideration of patient and disease characteristics in selecting radiation regimens for treatment of bone metastases. Pract Radiat Oncol 2017;7:403-410.

47. Deressa BT, Tigeneh W, Bogale N, et al. Short-course 2-dimensional radiation therapy in the palliative treatment of esophageal cancer in a developing country: a phase II study (Sharon Project). Int J Radiat Onco Biol Phys 2020;106:67-72.

48. Mudgal A, Arya AK, Yadav I, et al. Role of hypofractionated palliative radiotherapy in patients with stage four head-and-neck squamous cell carcinoma. J Cancer Res Ther 2019;15:528-532.

49. Stavas MJ, Shinohara ET, Attia A, et al. Short course high dose radiotherapy in the treatment of anaplastic thyroid carcinoma. J Thyroid Res 2014;2014:764281.

50. Bezjak A, Dixon P, Brundage M, et al. Randomized phase III trial of single versus fractionated thoracic radiation in the palliation of patients with lung cancer (NCIC CTG SC.15). Int J Radiat Oncol Biol Phys 2002;54:719-728.

51. Moeller B, Balagamwala EH, Chen A, et al. Palliative thoracic radiation therapy for non-small cell lung cancer: 2018 update of an American Society for Radiation Oncology (ASTRO) evidence-based guideline. Pract Radiat Oncol 2018;8:245-250.

52. Topkan E, Yildirim BA, Guler OC, et al. Safety and palliative efficacy of single-dose 8-Gy reirradiation for painful local failure in patients with stage IV non-small cell lung cancer previously treated with radical chemoradiation therapy. Int J Radiat Oncol Biol Phys 2015;91:774-780.

53. Kelly JF, Delclos ME, Morice RC, et al. High-dose-rate endobronchial brachytherapy effectively palliates symptoms due to airway tumors: the 10-year M. D. Anderson Cancer Center experience. Int J Radiat Oncol Biol Phys 2000;48:697-702.

54. Bach PB, Schrag D, Begg CB. Resurrecting treatment histories of dead patients: a study design that should be laid to rest. JAMA 2004;292:2765-2770. 